\title{
Computed Tomography Cisternography for the Management of Cerebrospinal Fluid Fistulae
}

\author{
${ }^{1}$ Mukund D Rahalkar, ${ }^{2}$ Anand M Rahalkar, ${ }^{3}$ Vardhan S Joshi, ${ }^{4}$ Kailash Sant, ${ }^{5}$ Kourabhi Zade
}

\begin{abstract}
Background: Chronic otitis media (COM) of mucosal type is a chronic condition of middle ear characterised by permanent perforation of tympanic membrane and hearing impairment, which is commonly seen in developing countries due to various factors such as low socioeconomic status, virulence of the organism, poor personal hygiene, increased antibiotic resistance, recurrent episodes of upper respiratory tract infections and inadequate health facilities. So, early and effective measures to be undertaken to prevent possible complications.
\end{abstract}

Aim: To determine whether there is any difference in bacterial isolates in clinically diagnosed chronic otitis media compared with adenosine deaminase enzyme (ADA) level proved chronic otitis media.

Materials and methods: Total 80 patients were included in the study selected on a random basis and divided into two groups. Group A consisted of 40 patients diagnosed clinically as chronic otitis media and group $B$ consisted of 40 patients diagnosed as ADA level proved chronic otitis media. The discharge was collected from the middle ear with a sterile cotton swab and sent to the microbiology department immediately for further processing of the sample and to identify the microorganisms. A blood sample is collected from 40 patients of group B to estimate the adenosine deaminase level.

Results: We have deciphered that Pseudomonas aeruginosa was the most common bacteria isolated in both the groups. In this study, none of the samples shows mixed growth or anaerobic organisms.

Conclusion: From this study, we concluded that the increased level of serum adenosine deaminase can be used as one of the indicative tools in chronic otitis media and its raise indicates the chronicity of the disease. ADA level will be an essential diagnostic tool in identifying the bacterial isolates.

Keywords: Adenosine deaminase lymphocytes, Ear discharge Microorganism, Sterile cotton swabs.

How to cite this article: Rahalkar MD, Rahalkar AM, Joshi VS, Sant K, Zade K. Computed Tomography Cisternography for the Management of Cerebrospinal Fluid Fistulae. Int $\mathrm{J}$ Otorhinolaryngol Clin 2017;9(3):93-95.

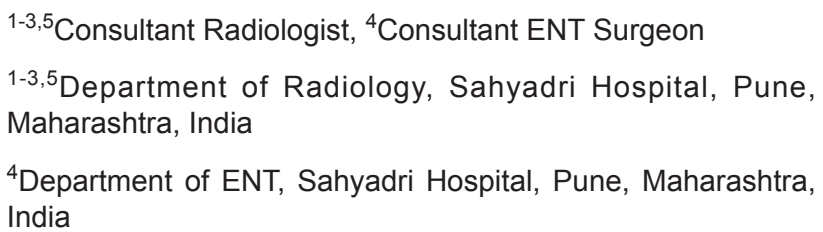

Corresponding Author: Mukund D Rahalkar, Consultant Radiologist, Department of Radiology, Sahyadri Hospital, Pune, Maharashtra, India, e-mail: mdrahalkar@hotmail.com

\section{Source of support: Nil}

Conflict of interest: None

\section{INTRODUCTION}

In recent years, the widespread use of antibiotics by the otorhinolaryngologists and other medical practitioners across the world in treating chronic otitis media leads to antibiotic resistance, with the emergence of multiple strains of bacteria and the development of more intracranial and extracranial complications. So, to prevent this the identification of microorganism is essential and to prescribe the proper antibiotics if required based on the sensitivity report. The microbial flora usually resides in the epithelium of the adenoid tissue, sinus mucosa, and oropharynx, and the eustachian tube facilitates easy entry of these bacteria into the middle ear cavity and to cause infection when the host immunity lowers down. ${ }^{1,2}$

Various studies showed that the most common organism isolated in chronic otitis media are Staphylococcus aureus, Pseudomonas aeruginosa, Klebsiella pneumonia, Escherichia coli and Proteus species. ${ }^{3}$

An ADA is one of the most essential immune enzymes because it has its role in the normal development of the immune mechanism along with the proper development of $\mathrm{T}$ and B-lymphocytes. ${ }^{4}$ The individuals are more susceptible to the bacterial or viral invasions when there is a reduction in the adenosine deaminase level. ${ }^{5}$

The objective of this study is to determine whether there is any difference in bacterial isolates in clinically diagnosed chronic otitis media compared with ADA level proved COM and to know the importance of serum adenosine deaminase level.

\section{MATERIALS AND METHODS}

The present study was conducted at JJM Medical College, Davangere on 80 patients of Indian nationality of either sex with discharging ear for more than 3 months duration after taking informed consent and required clearance from the Ethical committee. The study was conducted from January 2015 to July 2015. Group A includes 40 patients diagnosed clinically as chronic otitis media, and group B includes 40 patients diagnosed as ADA level proved chronic otitis media. Detailed clinical history, duration of discharge, usage of any previous antibiotics is taken. If 
the duration of ear discharge is less than 3 months duration, otitis externa, COM of squamosal type and patient presently on any antibiotics were excluded from the study.

Under strict aseptic precautions and with the help of a microscope, two sterile swabs were used to collect the discharge from the middle ear cavity through the perforation. The sample was transported to the microbiology department immediately for further processing. Based on the morphology, biochemical reactions and characteristics the isolated microorganisms were identified.

Out of 80 patients, venous blood samples were collected only from 40 patients (group B) under the aseptic condition, and ADA level was estimated.

\section{RESULTS}

In our study, the predominant bacteria isolated in group A (clinically diagnosed chronic otitis media) was Pseudomonas aeruginosa with 17 (42.5\%) isolates followed by Klebsiella with 13 (32.5\%) isolates and in group B (ADA level proved chronic otitis media of mucosal variety) the predominant bacteria isolated was Pseudomonas aeruginosa with 21(52.5\%) isolates followed by Staphylococcus species with 10 (25\%) isolates and the mean ADA level is $54.72 \mathrm{U} / \mathrm{L}$. No mixed growth or anaerobic organisms were seen in the culture media. The type of organisms isolated in groups A is shown in Table 1.

\section{DISCUSSION}

Chronic otitis media (COM) is characterized by recurrent ear discharge and gradually progressive conductive hearing loss. It is more common in lower socioeconomic status and rural population. ${ }^{6,7}$ Because of its chronicity, it can lead to many complications like deafness, facial nerve paralysis, labyrinthitis, mastoiditis, petrositis, meningitis, brain abscess, lateral sinus thrombophlebitis.

Adenosine deaminase activity increased due to antigenic stimulation leading on to rapid proliferation of T-lymphocytes and these lymphocytes prevents the accumulation of toxic products released from the antigen. Thus, it was considered as a marker to determine cellmediated immunity. Certain diseases like tuberculosis, typhoid showed an increased level of ADA., ${ }^{8}$

Table 1: Organisms isolated in groups $A$ and $B$

\begin{tabular}{|c|c|c|c|c|}
\hline \multirow[b]{2}{*}{ Organisms } & \multicolumn{2}{|l|}{ Group A } & \multicolumn{2}{|l|}{ Group B } \\
\hline & $\begin{array}{l}\text { Number of } \\
\text { isolates }\end{array}$ & $\%$ & $\begin{array}{l}\text { Number of } \\
\text { isolates }\end{array}$ & $\%$ \\
\hline $\begin{array}{l}\text { Pseudomonas } \\
\text { aeruginosa }\end{array}$ & 17 & 42.5 & 21 & 52.5 \\
\hline $\begin{array}{l}\text { Staphylococcus } \\
\text { species }\end{array}$ & 00 & 00 & 10 & 25.0 \\
\hline Klebsiella species & 13 & 32.5 & 04 & 10.0 \\
\hline Escherichia coli & 09 & 22.5 & 04 & 10.0 \\
\hline Proteus mirabilis & 01 & 02.5 & 01 & 02.5 \\
\hline
\end{tabular}

Table 2: Analysis of bacterial

\begin{tabular}{|c|c|c|}
\hline Authors & $\begin{array}{l}\text { Predominant organisms } \\
\text { isolated }\end{array}$ & $\%$ \\
\hline Goyal et al. ${ }^{11}$ & Pseudomonas aeruginosa & $47.4 \%$ \\
\hline Harvinder et al. ${ }^{12}$ & Pseudomonas aeruginosa & $45.5 \%$ \\
\hline Afolabi et al. ${ }^{13}$ & Pseudomonas aeruginosa & $31.3 \%$ \\
\hline Malkappa et al. ${ }^{14}$ & Pseudomonas aeruginosa & $45.2 \%$ \\
\hline Kuchhal et al. ${ }^{15}$ & Staphylococcus aureus & $38.4 \%$ \\
\hline Taneja et al. ${ }^{16}$ & Staphylococcus aureus & $33.3 \%$ \\
\hline Our study & Pseudomonas aeruginosa & $42.5 \%$ \\
\hline
\end{tabular}

In our study, we confirm that the level of ADA is increased in the patients suffering from chronic otitis media. Mishra et al., ${ }^{10}$ reported that lymphocytic proliferation and differentiation occurs because of ADA. This was the reason for the serum adenosine deaminase level to increase in chronic inflammatory conditions.

The analysis of the bacterial flora in our study showed (Table 2) Pseudomonas aeruginosa is the most common organism isolated in group A (clinically diagnosed COM) and group B (ADA level proved COM). Our results are concordance with Goyal et al., ${ }^{11}$ Harinder et al., ${ }^{12}$ Afolabi et al. ${ }^{13}$ and Malkappa et al., ${ }^{14}$ Kuchhal et al., ${ }^{15}$ studied 75 subjects and found Staphylococcus in the maximum number of cases, followed by Pseudomonas. The most common organism by Mansi et al. and Taneja ${ }^{16}$ was Staphylococcus aureus. Pseudomonas aeruginosa is a highly virulent microorganism commonly seen in the immunocompromised host. ${ }^{17}$ Its increased antigenic property is because of its resistance to phagocytosis and opsonization by releasing a large number of intracellular products like exotoxin $\mathrm{A}$, protease and elastase which alters both the compliment and $\mathrm{IgG}$ resulting in a reduced function of immune cells. ${ }^{18,19}$

However, in our study, we found that organism isolated in group B (ADA level proved chronic otitis media) is Staphylococcus species next to pseudomonas which accounts for $25 \%$ of the total isolates. Kuchhal et al., ${ }^{15}$ and Mansi et al. ${ }^{16}$ reported Staphylococcus in the maximum number of cases, followed by Pseudomonas.

Coliforms including Escherichia coli and Klebsiella were isolated from both group A (clinically diagnosed COM) and group B (ADA level proved COM). Our results are concordance with Poorey and Iyer et al. ${ }^{20}$ reported $25.4 \%$ of Klebsiella species.

In our study, Proteus mirabilis constitutes $2.5 \%$ of total isolates in both groups A and B. It is the invader from the external auditory canal and shows its antigenicity when the host immune response was lowered.

When compared with other studies and the organisms isolated in our study, we have found that the organisms isolated was almost the same except for Staphylococcus aureus. 


\section{CONCLUSION}

Bacterial predominance change over time due to the climate, antibiotic, and geographical factors. As there is difference noticed in various studies regarding bacterial isolates in chronic otitis media, estimation of serum adenosine deaminase level will be an essential diagnostic tool in identifying the bacterial isolates and its effective treatment and outcome.

\section{REFERENCES}

1. Ahmed A, Usman J, Hashim R. Isolates from CSOM, their antimicrobial sensitivity. Armed Forces Med J 1999;49(2):82-85.

2. Vartiainen E, Vartiainen J. Effect of aerobic bacteriology on clinical presentation and treatment results of CSOM. J Laryngo-Oto, 1996;110(4):315-318.

3. Jakimovska F, Cakar M, Lazarevski A, et al. CSOM-Microbiological findings. Balkan J Otolneurootol 2002;426-428.

4. Hirschhorn R. Overviews of biochemical abnormalities and molecular genetic of adenosine deaminase deficiency. Pediatr Res 1993;33:335-341.

5. Blease RM. Relationship between ADA level and type of bacterial causative agents of chronic suppurative otitis media. Science.1989;246:751.

6. Anifasi WB, Tumushime-Buturo CG. Bacteriology and drug sensitivity of chronic suppurative otitis media in central hospital in Zimbabwe. Cent Afr J Med 1989;35: 481-483.

7. Fairbanks D. Pocket Guide to antimicrobial therapy in Otolaryngology- Head and Neck Surgery. In Alexndria VA, editor. 8th ed. The American Academy of OtolaryngologyHead and Neck Surgery Foundation. 1996. p. 1-91.
8. Piras MA, Gakis C, Brudroni M, et al. Adenosine deaminase activity in pleural effusions; an aid to differentiate the diagnosis. Br Med J 1978,2:1751-1752.

9. Baganha MF, Pego A, Lima MA, et al. Serum and pleural adenosine deaminase - correlation with lymphocytic populations. Chest 1990,97:605-610.

10. Mishra OP, GuptaBL, Ali Z, et al. Adenosine deaminase activity in typhoid fever. Indian Pediatr 1994;31(11);1379-1384.

11. Goyal R, Aher A, DeS, et al. Chronic suppurative otitis media- A clinico- Microbiological Study. Indian J Otol 2009;15:18-22.

12. Kumar H, Seth S. Bacterial and fungal study of 100 case of CSOM. Journal of Clinical and Diagnostic Research 2011;5(6):1224-1227.

13. Afolabi OA, Salaudeen AG, Ologe FE. Pattern of bacterial isolates in the middle ear discharge of patients with chronic suppurative otitis media in North Central Nigeria. Afr Health Sc. 2012;12(3):362-367.

14. Malkappa SK. Study of aerobic bacterial isolates and their antibiotic susceptibility pattern in chronic suppurative otitis media. Indian J Otol 2012;18:136-139.

15. Kuchhal V. Antibiotic sensitivity pattern in chronic suppurative otitis media in kumoun region. Indian J Otol 2010;16:17-21.

16. Taneja M, Taneja MK. CSOM a bacteriological study. Indian J Otol 2009;15:3-7.

17. Johnson RI. Chronic otitis media in school age Navajo Indians. Laryngoscope 1967;78:1990-1995.

18. Stenfors LE, Raisanen S. Is attachment of bacterial to the epithelial cells of the nasopharynx the key to otitis media. Int J Pediatr Otorhinolaryngol 1991a;22:1-8.

19. Stenfors LE, Raisanen S. Opsonization and phagocytosis of bacteria during various Middle ear infections. Int J Pediatr Otorhinolaryngol 1991;27:137-145.

20. Poorey VK, Lyer A. Study of bacterial flora in csom and its clinical significance. Indian J Otolaryngol Head and Neck Surgery 2002;54;91-95. 